\title{
INTERCULTURALIDADE E ENSINO DE LÍNGUAS
}

Raquel Alves Ishii ${ }^{1}$

\section{RESUMO}

Com o presente ensaio tem-se o objetivo de pontuar reflexões sobre a constituição de uma prática intercultural mediada pela linguagem no ensino de línguas na escola de educação básica. A reflexão centra-se nas questões de identidade e alteridade no ensino de línguas, considerando o papel relevante desse debate durante o processo de formação inicial. A partir do conceito de interculturalidade de Catherine Walsh $(2011,2009)$ e pensando a diferença na escola como parte de uma visão não excludente ou dicotômica da igualdade e da diferença de Vera Candau (2012), propõe-se um repensar do papel do "professor de língua estrangeira", e do próprio professor, com vistas à promoção de relações dialógicas entre línguas/culturas e entre professores e alunos.

\section{PALAVRAS-CHAVE:}

Linguagem e Educação. Ensino de Língua. Cultura. Interculturalidade.

\section{INTERCULTURALITY AND LANGUAGE TEACHING}

\section{ABSTRACT}

The purpose of this essay is to reflect on a constitution of an intercultural practice mediated by language in foreign language teaching in Basic Education. The reflection is centered on the concepts of identity and otherness in language teaching, considering the relevant role of this debate during the initial formation process of teachers. From Catherine Walsh $(2011,2009)$ intercultural concept and the view of equality and difference by Vera Candau (2012), it is proposed to rethink the role of the "foreign language teacher", and the teacher himself, with perspectives of promoting dialogic relations between languages / cultures and between teachers and students.

\section{KEYWORD:}

Language and Education. Language Teaching. Culture. Interculturality.

Mestra em Letras: Linguagem e Identidade pela Universidade Federal do Acre (2011) e professora dessa mesma Instituição Federal de Ensino, com atuação no Curso de Letras - Inglês. A versão inicial deste artigo foi elaborada e apresentada durante o XVI Seminário Repensando as Práticas de Ensino dos Cursos de Letras, realizado no período de 11 a 14 de julho de 2017, no câmpus da Universidade Federal de Rondônia. 


\section{Introdução}

0 debate em torno da interculturalidade na América Latina tem lugar nas lutas e movimentos indígenas, em especial, no Equador e na Bolívia, durante a década de 1990, e tem atravessado os estudos culturais, pós-coloniais e decoloniais de autores como Catherine Walsh e Néstor Garcia Canclini. No Brasil, no campo da educação, centro de nossas atenções, convém destacar as reflexões em torno da identidade e alteridade propostas por Tomaz Tadeu e Silva, Carlos Bernardo Skliar e Vera Maria Candau, cujo diálogo com autores como Boaventura de Souza Santos, Stuart Hall, Beatriz Sarlo, dentre outros, permitem trilhar o caminho da relação dialógica presente nas relações sociais e na linguagem, aqui compreendida enquanto uma prática situada histórica e socialmente.

\section{Considero importante} inicialmente reforçar o quanto nós, professores amazônicos de línguas denominadas como "estrangeiras" - a exemplo do Inglês e do Espanhol -, estamos diante da perspectiva da interculturalidade não apenas de ensino, mas de re- estruturação de relações que não foram forjadas em academias, por especialistas do conhecimento sejam europeus ou norteamericanos. É curioso observar o quanto a universidade e a escola têm a perder quando decide encastelar-se em seus campos de saber/poder e o quanto temos a aprender ouvindo intelectuais indígenas como Eliane Potiguara, Narubia Werreria, Graça Graúna, Edson Kayapó, Gersem Baniwa, Joaquim Maná Kaxinawá, Ibã Huni Kuin, Cristino Wapichana, Daniel Munduruku ou a Silvia Rivera Cusicanqui, socióloga boliviana aimara, que é uma referência para nós que propomos desenvolver estudos de crítica ao binômio modernidade/colonialidade.

É graças à agência desses sujeitos e à disposição de ouvi-los que podemos compreender melhor os contornos de uma educação intercultural na Amazônia e na Pan-Amazônia, especialmente, porque transitar em duas ou mais línguas permite o acesso a matrizes culturais diferentes que divergem, convergem ou complementam-se. Nessa direção, me alio aos autores que buscam, de início, desconstruir a noção de língua vinculada 
à identidade nacional, como Kanavilil Rajagopalan, Domingos Sávio, Telma Gimenez, Kramsch, Uryo e Kachru, dentre outros, que defendem uma língua inglesa desterritorializada (e creio que não seria diferente com o espanhol se pensarmos na hegemonia da variação do espanhol standard da Espanha e nas variações por toda a América hispânica), considerando que há atualmente mais falantes de língua inglesa fora dos países considerados seus centros originários - como a Inglaterra e os Estados Unidos -, do que nesses países juntos. Países que utilizam a língua inglesa como segunda língua ou como língua de contato comercial - Índia, Nigéria, China, Japão - há muito já se apropriaram do inglês e o "contaminaram" no cotidiano vivo de suas línguas maternas, crioulizando-o nas trocas provenientes do contato intercultural (via de regra, assimétrico) e utilizando-o para propósitos comunicativos os mais variados de produção e difusão de conhecimento.

Frente a esse cenário em que a variação linguística cresce na medida em que as línguas irrompem fronteiras nacionais, como professores de línguas, precisamos nos perguntar: qual variação ensinar? Que práticas culturais abordar? Manter o foco na língua e literatura vinculada à identidade nacional de países como Inglaterra e Estados Unidos (ou Espanha) em nossos materiais didáticos e abordagens considerando que o outer circle de Kachru data de 1985 - se constitui em, no mínimo, um anacronismo.

No entanto, diferentemente dos estudos dos autores referidos - que nos levam a uma importante compreensão da língua inglesa como lingua franca ou pensada nos moldes de um World English apropriado das mais distintas formas pelos quatro continentes -, minha reflexão gira em torno das questões de identidade e alteridade no ensino de línguas, por considerar a centralidade desse debate durante o processo de formação inicial. Creio que reside nisso uma espécie de convite para repensarmos nossas práticas e nossas epistemologias etnocêntricas.

As fronteiras do eu-outro

Inicio me referindo ao conceito de fronteiras e não trarei aqui nenhuma definição científica, 
mas sim uma reflexão do escritor moçambicano, Mia Couto, que não deixa de possuir natureza teórica e metodológica, mas, acima de tudo, se demonstra profunda e desestruturante:

Nosso pensamento, como toda a entidade viva, nasce para se vestir de fronteiras. Essa invenção é uma espécie de vício de arquitetura: não há infinito sem linha do horizonte. Desde a mais pequena célula aos organismos maiores, o desenho de toda a criatura pede uma capa, um invólucro separador. A verdade é esta: a vida tem fome de fronteiras. É assim que se passa e não haveria nada a lamentar. Porque essas fronteiras da natureza não servem apenas para fechar. Todas as membranas orgânicas são entidades vivas e permeáveis. São fronteiras feitas para, ao mesmo tempo, delimitar e negociar. 0 "dentro" e o "fora" trocam-se por turnos (COUTO, 2012).

"Todas as membranas orgânicas são entidades vivas e permeáveis", diz o poeta da prosa, de modo que as fronteiras no mundo natural são feitas ao mesmo tempo para "delimitar" e "negociar". Assim, a própria troca entre os de dentro e os de fora já está dada a partir dessa fronteira/ membrana. No entanto, ao passo que as fronteiras da natureza não servem apenas para fechar as fronteiras culturais, definidas histórica e socialmente, não podemos pensá-las somente como lugares que separam, cindem, dividem.

0 que se coloca diante de nós, na esteira de Mia Couto é o repensar as fronteiras entre 0 eu e o outro, de modo a vê-las não como lugar de separação, mas como lugar de encontro e de trocas. Ao invés de pensarmos o "eu" separado do "outro" por uma conjunção aditiva e um artigo definido, talvez pudéssemos reescrever ou mesmo inscrever a relação do eu-outro tomando o hífen como elemento base que, ao mesmo tempo, separa e une os dois pólos. Desse modo, além de não reforçar semanticamente mais uma das tantas dicotomias cotidianas que nos reduzem as possibilidades de imaginar/ pensar o mundo, repensaríamos a relação eu-outro não como pólos que se contrapõem, mas como pólos que se exigem mutuamente. Repensar a relação eu-outro é tão importante quanto evidenciar que a dialogia que marca essa relação é acompanhada pela tensão e pelo conflito, afinal "a vida tem fome de fronteiras" e é 
preciso compreender aquilo que no "eu" diluiu-se em alteridade e o que não se deixou cindir nesse processo, constituindo identidade (GLISSANT, 2005).

0 "outro", visto como oposição do "eu", em sociedades fundadas sob a égide da razão "ocidental", é caracterizado como nosso inimigo e, por vezes, o é, considerando as contínuas práticas de intolerância e discriminação que se manifestam na eliminação física e simbólica daqueles que pensam diferente de nós. Esse mesmo "outro" tem sido visto como o elemento estranho e estrangeiro, considerando que na relação de alteridade o que temos é que

Uns são bons, os verdadeiros, os autênticos, os civilizados, os cultos, os defensores daliberdade e da paz. Os "Outros" são maus, falsos, bárbaros, ignorantes, terroristas. Se nos situarmos nos primeiros, o que temos de fazer é eliminar, neutralizar, dominar ou subjugar o "outro". Caso nos sintamos representados como integrantes do pólo oposto, ou internalizamos nossa 'maldade' e nos deixamos 'salvar', passando para o lado dos 'bons' ou nos confrontamos violentamente com eles (CANDAU, 2012, p. 30).

Em que pólo nos encontramos? Somos o "outro" de quem? Quem são nossos "outros"?
Quem é o estrangeiro, o falante de outra língua? Como professores de línguas, somos então os "estrangeiros" de nossos alunos? Evidentemente, um debate que nos confinasse em um dos pólos em definitivo seria aporético e sem sentido para as questões que realmente importam, pois,

o "estrangeiro", (...) não poderia simplesmente ser condenado a ser o "nosso" "oposto", pois, no dizer de Julia Kristeva, "estranhamente, o estrangeiro habita em nós". Embora seja considerado historicamente o "símbolo do ódio e do outro, o estrangeiro não é nem a vítima romântica de nossa preguiça habitual, nem o intruso responsável por todos os males da cidade" (ISHII, 2011, p. 111).

Quantos de nós não fomos surpreendidos como possuidores de um sotaque que sequer percebíamos eao viajar para outras cidades brasileiras e entrar em contato com outros sotaques, nos vimos obrigados a assumir uma determinada identidade marcada pela língua? Quantos de nós não carregamos deslocamentos e exílios em nossas trajetórias de vida, a ponto de não sermos mais reconhecidos como "os de dentro" em nossa cidade natal, ao mesmo tempo em que seremos quase sempre reconhecidos como os "de 
fora" em terras distantes? Quantos de nós, por circunstâncias diversas, se distanciam de grupos de amigos ou familiares e percebem, depois de alguns anos, que as relações não voltam no tempo com o retorno da aproximação ou convivência no mesmo espaço - muitas vezes, os re-encontros são, na verdade, encontros de pessoas estranhas umas as outras. Situações como essas nos colocam diante do "estrangeiro" que habita em nós e dentro do que entendemos como nosso "território nacional".

Ao repensar nosso papel enquanto professores de línguas "estrangeiras" nos colocaremos diante da necessidade de repensar o estrangeiro da língua. Como seguir falando em línguas "estrangeiras" (e modernas!) quando vivemos um constante e permanente deslocamento, no qual as fronteiras internas e as nacionais assumem um caráter tão fluído e poroso que não permitem que nos fixemos por muito tempo em lugar algum ou em identificação alguma. Somos cada vez mais convidados a ser cidadãos/cidadãs do mundo e não de um lugar específico. Mais do que professores de Língua Estrangeira
Moderna ou de Língua Inglesa ou de Língua Espanhola, temos sido Professores de Linguagem.

Retorno mais uma vez a Mia Couto que nos apresenta em um cenário da vida natural, uma excelente metáfora de nossa vida social:

Um dos casos mais notáveis na construção de fronteiras acontece no mundo das aves. É o caso do nosso tucano, o tucano africano, que fabrica o ninho a partir do oco de uma árvore. Nesse vão, a fêmea se empareda literalmente, erguendo, ela e o macho, um tapume de barro. Essa parede tem apenas um pequeno orifício, que é a única janela aberta sobre o mundo. Naquele cárcere escuro, a fêmea arranca as próprias penas para preparar o ninho das futuras crias. Mesmo que quisesse desistir da empreitada, ela morreria, sem possibilidade de voar. 0 amor dá ordem de prisão àquela futura mãe. A pequena abertura na parede servirá, durante duas a três semanas, para que o seu companheiro lhe entregue comida e água. Se o macho morrer, ela morre também.

Usando a lógica de Manoel de Barros o que aqueles pássaros construíram não foi uma parede. Foi um buraco. 0 que eles edificaram foi um vazio, uma redonda ausência de tudo. Mesmo neste caso extremo, porém, mesmo neste caso de consentida clausura, a divisória 
foi inventada para ser negada.

o problema é que o nosso pensamento, ao contrário das restantes entidades vivas, facilmente se encerra em si mesmo. Não sabemos fazer paredes vivas e permeáveis. Erguemos paredes inteiras como se fôssemos tucanos cegos. De um e do outro lado há sempre algo que morre, truncado do seu lado gêmeo (COUTO, 2012).

Inspirada nessa percepção de Mia Couto, acredito que o que precisa ser repensado em nosso pensamento é a relação de interdependência entre o eu e o outro. Se nosso outro morrer, morremos também, pois eu me defino a partir dele e ele de mim. Quanto às fronteiras que nos separam, estas haveriam de ser repensadas como construções vivas e permeáveis, rígidas o suficiente apenas para que nenhum dos pólos se sobreponha ao outro. No campo do ensino de línguas, frequentemente nos colocamos diante das relações de alteridade e criamos circunstâncias de contato cultural ao trabalharmos com uma língua que não a "portuguesa"2.

2 Depois das reflexões de Marcos Bagno na Gramática Pedagógica do Português Brasileiro (2012), dificilmente temos como sustentar uma definição que não a do Português Brasileiro ao invés da Língua Portuguesa, como forma de marcar o contato ameríndio
Por vezes, em decorrência de termos sido formados por uma escola que busca na padronização a expressão do sucesso na aprendizagem, desconhecemos o "eu" (o diferente) e fazemos a opção apenas pelo "outro" (o padrão). As aulas que se seguem, são carregadas pelos valores culturais (entendidos como fixos) de uma língua que não a nossa, sem a devida mediação característica de um contato dialógico.

Em geral, no que se refere aos conteúdos sistêmicos ou linguísticos, esteja presente uma abordagem tradicional ou não, escolhemos quase sempre a língua inglesa norte-americana padronizada como parâmetro ideal de realização sonora e muitas são as horas gastas com a correção do th sound. Insistimos em exercícios de conjugação da $3^{\mathfrak{a}}$ pessoa do singular, quando boa parte dos falantes de língua inglesa na Norte América fala He don't e She do, com a mesma naturalidade que falamos tu vai ao invés de tu vais. Do mesmo modo, na disciplina de língua espanhola, insistimos que nossos alunos falem com ceceo, assim como o standard da língua

(transformador) com a língua européia - o português lisboeta. 
espanhola, apesar dessa marca não ser frequente em toda Espanha e quase inexistir em países da América Latina rio-platense, como é o caso do Uruguai e Argentina ${ }^{3}$.

São nessas e noutras circunstâncias de contato, aparentemente inocentes, que reproduzimos uma lógica de exclusão das outras possibilidades de sentidos na realização da língua e é por meio dessa inocente abordagem padronizadora, ao invés de problematizadora das diferentes formas produção oral da língua, que perdemos a chance de enfatizar a dimensão axiológica que marca as variantes de prestígio e que excluem as demais no mesmo movimento que excluem sujeitos.

Com a língua inglesa, projetamos ainda o sonho americano e colaboramos para constituir um estereótipo em torno do imaginário reproduzido por um cinema que promove americanos como heróis não apenas de sua nação, mas heróis mundiais contra alienígenas, zumbis, traficantes e terroristas.

3 Muitas das referências ao ensino de língua espanhola são contribuições dos diálogos com a Professora Mestra Francemilda Lopes do Nascimento, do Curso de Letras/Espanhol da Universidade Federal do Acre.
A reprodução desse estereótipo fetichizado em torno do americano é a expressão da relação colonial que estabelecemos na alteridade que marca as nossas salas de aula. Ouvimos denossos professores: "só o fato de você saber falar a língua inglesa, já deve te dar vantagens no mercado de trabalho", ou seja, o fato de você falar inglês te fará melhor que os demais e melhor do que você já é. E é aqui que o eu é visto como oposto ao outro. Um dos lados da relação que deveria ser de interdependência morre: o eu desintegrou-se no outro por completo. 0 que resta é um simulacro: alguém que não sabe quem é e foi levado a decidir não ser quem é.

Igualdade e diferença

0 ensino intercultural, não apenas de línguas, se caracteriza pela mediação entre igualdade e diferença. Igualdade de direitos ou igualdade pelo "direito a ter direitos", bem como o direito a ser diferente, não padronizado. Aqui, mais uma vez, nos afastamos das lógicas binárias: o oposto da igualdade não é a diferença. 0 oposto de igualdade é a desigualdade e esta deve ser combatida. Igualdade e diferença, 
portanto, não são pólos que se contrapõem, mas pólos que se exigem mutuamente (CANDAU, 2012). A diferença é, pois, constitutiva de qualquer processo de formação cultural e é por isso mesmo que a escola não pode se comportar como o receptáculo da diferença, ou seja, receber a diferença, conceder-lhe um espaço, tolerar-lhe. A diferença precisa constituir o currículo e as formas de simbólicas de construção do conhecimento, do mesmo modo que estará presente nas relações interpessoais e nos projetos de ensino sem que sejam destinados dias especiais, feriados folclorizantes como é o dia do índio, da consciência negra, do meio ambiente, ou, em se tratando das disciplinas de língua espanhola e inglesa: el día de la hispanidad, el día de la raza, Halloween, Thanksgiving e, o que tenho visto como mais bizarro, a comemoração da independência dos Estados Unidos em nossas escolas, the 4th of July, dentre tantos outros regulados pela lógica de consumo alucinado do mercado sem fronteiras: Mother's Day, Father's Day, Valentine's Day, etc.
Um projeto de escola que não se funda na compreensão constitutiva da diferença somente poderá enxergá-la como essencializada, fixa e singular, resultando em ações iluministas que buscam "incluir", "tolerar", "reconhecer", mas não se predispõem a repensar estruturalmente suas relações de produção e difusão do conhecimento. É nesse sentido que entendamos a proposta do trabalho em torno do tema transversal "pluralidade cultural" definido nos Parâmetros Curriculares Nacionais do Ensino Fundamental (1997), que se propõe reconhecer e incluir as diferenças com vistas a construir um ambiente escolar que em se possa tolerá-las. 0 discurso da inclusão e do respeito, em que pese o positivo aspecto da denúncia contra a violência física e discriminação de raça, gênero, religião e orientação sexual, por vezes, acabam por ser utilizados por instituições governamentais ou não-governamentais como formas de legitimação de uma imagem supostamente democrática que encobre as relações desiguais estruturantes.

A diferença, pois, continua 
sendo uma peça menor de um sistema já constituído, já formado, que não abre espaço para que se possa repensá-lo, (re)estruturálo, a partir da diferença. O modelo institucional de escola que temos continua indiferente aos processos interculturais que definem as culturas, em especial, as culturas ameríndias, pois continua a basear-se em um conceito de cultura como algo fixo e essencializado, bem como continua a sustentar como relação de oposição e não como relação de complementaridade, os conceitos de igualdade e diferença em sua busca pela padronização e pela homegeneização - a que chamam de igualdade. Qual professor de língua inglesa ou espanhola nunca se ressentiu de ter turmas heterogêneas, justificando os problemas de aprendizagem dos alunos a partir da diferenças de "níveis" de conhecimento e propondo como solução (inovadora!) a divisão dos alunos mais "proficientes" dos alunos menos "proficientes"?

Se tivéssemos um medidor do nível de interculturalidade em nossas práticas, descobriríamos sem muitas surpresas que continuamos seguindo o caminho da padronização e da eliminação das diferenças, assentados em uma visão de cultura como imutável, atávica.

Assim, a pergunta que nos fica é a que foi formulada por Catherine Walsh (2011, p. 93): 0 que entendemos por interculturalidade? É uma proposta e uma política de "reconhecimento e inclusão nos Estados-nações estabelecidos"? E/ou uma aposta que procura incidir e in-surgir" nas estruturas de poder ainda colonial-racial?

A interculturalidade não é, pois, um instrumento ou uma ferramenta de ensino, mas um processo ou, no dizer de Walsh, uma aposta que procura incidir, afetar e insurgir, eu diria, nos sistemas de pensamento ou nos pensamentos-sistema, como nos define Édouard Glissant.

Assim é preciso compreender a interculturalidade como um

processo e projeto social, político, ético e epistêmico. Como um princípio ideológico e político, inicialmente proposto pelo movimento indígena equatoriano, e não um conceito concebido a partir da academia - a interculturalidade limpa horizontes e abre caminhos 
que enfrentam o colonialismo ainda presente, convidando a criar posições e condições, relacionamentos e estruturas novas e distintas (WALSH, 2009, p. 14. Minha tradução.).

Pensar o intercultural, nos marcos propostos por Walsh, é deslocar do produto para o processo, do conceito para o projeto, do colonial para o decolonial:

A interculturalidade é um projeto que, por necessidade, convoca a todos os preocupados com as relações de poder - que mantêm e continuam a reproduzir o racismo, a racialização, a desumanização de alguns e a super e sobrehumanização de outros, a subalternização dos seres, conhecimentos e formas de viver. Seu projeto é a transformação social e política, a transformação das estruturas de pensar, agir, sonhar, ser, estar, amar e viver. (...) Em si mesma, não temos a intenção de apresentar a interculturalidade como um novo paradigma totalizante, mas como uma perspectiva, processo e plano de vida a construir (WALSH, 2009, p.15. Minha tradução).

Para encerrar essas breves notas anti-dicotômicas, chamo a atenção para a necessidade de repensarmos o ser professor e o ser aluno. Em primeiro lugar, cabe uma referência e uma defesa em torno do direito à transitoriedade do ser, o que nos levaria a repensar o verbo no infinitivo por um presente contínuo que marcasse a continuidade do trânsito que opera a identidade e a alteridade de cada um. Somos sendo professores e alunos em uma contínua alternância sempre conflituosa e desconcertante.

Em segundo lugar, Paulo Freire (1996), com sua dialogização das relações, mas também com a sua crítica às desigualdades sociais estruturantes de nossas sociedades, nos permite ter clareza dos processos de negação das alteridades ou dos processos de desumanização a que estamos expostos, em especial na América Latina, que nos retiram o direito a ser e a ser mais. Não se trata de um ser ontológico, mas um ser humano, um sujeito históricosocial capaz de transformar as relações sociais.

Nessa esteira, ao pensamos nossa sala de aula, evidenciamos que

Os alunos estão exigindo de nós, educadores/as, novas formas de reconhecimento de suas alteridades, de atuar, negociar, dialogar, propor e criar. Estamos desafiados a superar uma visão padronizadora de suas identidades. Trata-se de 
abrir espaços que nos permitam compreender essas novas configurações identitárias, plurais e fluidas, presentes nas nossas escolas e na nossa sociedade (CANDAU, 2012, p. 60).

Essa exigência a que se refere Candau, exigência por igualdade de direitos e pelo exercício da diferença, questiona não apenas nossas práticas docentes, mas também nossos currículos marcados por epistemologias colonizadas. Dificilmente poderemos falar em ensino intercultural quando há negação de alteridades. Não se pode basear o ensino-aprendizagem em "superação de diferenças", como se fossem desigualdades, na busca de resultados hegemônicos a partir de contextos heterogêneos. A diferença cultural enquanto expressão da identidade e alteridade de sujeitos sociais não precisa ser superada, precisa ser evidenciada, buscada, servindo de base para um re-ordenamento epistemológico da escola, do currículo e das práticas sociais e simbólicas não apenas dos docentes ou professores, mas da comunidade escolar como um todo em um "reinventar da escola", no dizer Candau, de modo a construir um projeto que negue a padronização e que combata todas as formas de desigualdade e discriminação. "Nem a padronização, nem a desigualdade" (CANDAU, 2012, p. 27).

Nesse contexto, os professores de línguas se apresentam como agentes importantes na construção de alteridades, a partir da elevação da auto-estima e na desconstrução de estereótipos, com vistas a produzir circunstâncias de contato cultural mais democráticas COM os alunos e NÃO PARA OS ALUNOS, como nos alerta Paulo Freire.

Este cenário nos impõe a difícil e necessária condição de repensar o ser professor e o ser aluno no âmbito de suas identidades e alteridades, de uma compreensão do conceito de cultura que não seja essencializante das relações sociais e de desconstrução de visões hierarquizantes entre seres e saberes.

Ademais, não temos o direito de não enfatizar que as dificuldades cotidianas têm promovido limitações sobre o fazer docente. Mas, há também que entendêlas exatamente em um contexto 
de uma política que se vale da desvalorização salarial, da falta de condições adequadas de trabalho e da violência física e simbólica, para melhor implementar um ritmo de intensificação e precarização ou proletarização do trabalho docente com vistas a reduzir a capacidade de enfrentamento intelectual da escola de resultados, da mercadorização do ensino, da visão operacional dos processos de ensino-aprendizagem e a da falta de intencionalidade pedagógica das ações de professores, além dos ataques conservadores como o movimento Escola Sem Partido ou mesmo aos processos de privatização interna.

Assim, como o projeto intercultural não nasceu na academia, mas do seio de movimentos sociais indígenas, as transformações mais significativas das relações no campo educacional estão se dando a partir de demandas externas à lógica homogeneizante da escola e não pelas vias institucionais. Nessa direção, o diálogo entre o professor e o aluno e a sua relação de interdependência nunca foi tão importante como agora e se constitui como ferramenta de fundamental importância para os desafios do momento presente, da vida presente, das lutas de mulheres e homens dos obscuros tempos presentes.

\section{Referências}

CANDAU, V. M. (Org.). Didática Crítica Intercultural: aproximações. Petrópolis, RJ: Vozes, 2012.

COUTO, M. Repensar o pensamento, redesenhando fronteiras. In: MACHADO, C. Elek. (Org.). Pensar a cultura. Porto Alegre: Arquipélogo Editorial, 2012. Disponível em https://goo.gl/ceHC9L. Acesso em 06 jul 2017.

FREIRE, P. Pedagogia do oprimido. São Paulo: Editora Paz e Terra, 1996. GLISSANT, E. Introdução a uma poética da diversidade. Juiz de Fora: Editora UFJF, 2005.

RAJAGOPALAN, K. O "World English"- Um Fenômeno Muito Mal Compreendido. In: GIMENEZ, Telma. CALVO, Luciana. EL KADRI Michele. (Orgs.). Inglês como Língua Franca: Ensino-Aprendizagem e formação de professores. Coleção: Novas Perspectivas em Linguística Aplicada Vol.14.Campinas, SP: Pontes Editores, 2011. P. 45-57.

SIQUEIRA, D. S. P. Inglês como língua Franca: O Desafio de Ensinar um Idioma Desterritorizado.In: GIMENEZ, Telma. CALVO, Luciana. EL KADRI Michele. (Orgs.). Inglês como Língua Franca: Ensino-Aprendizagem e formação de professores. Coleção: Novas Perspectivas em Linguística Aplicada Vol. 14. Campinas, SP: Pontes Editores, 2011. P. 87-115. 
WALSH, C. Etnoeducación e interculturalidad en perspectiva decolonial. In: Desde adentro: etnoeducación e interculturalidad en el Perú y América Latina. Lima: CEDET, Centro de Desarrollo Étnico, 2011.

WALSH, C. Interculturalidad, estado, sociedad: luchas (de)coloniales de nuestra época. Universidad Andina Simón Bolívar: Ediciones Abya-Yala, Quito, 2009. 